\title{
POSICIONAMENTOS INTERACIONAIS DE SEXUALIDADE E DE GÊNERO: O CASO DE UM BLOG DE ALUNAS/OS DE UM INSTITUTO FEDERAL
}

\section{INTERACTIONAL POSITIONINGS OF SEXUALITY AND GENDER: THE CASE OF A STUDENT BLOG AT A FEDERAL INSTITUTE}

\section{Valéria Rezende Pereira*}

\section{RESUMO}

Neste artigo, procuro expor alguns apontamentos sobre os posicionamentos interacionais de sexualidade e de gênero observados em um dos artigos de opinião no blog Integra, criado por alunas/os de um Instituto Federal de Minas Gerais, bem como identificar as ordens de indexicalidade de sexualidade e de gênero presentes nesse blog. O escopo teórico valeu-se das concepções de atos de fala performativos discutida por Austin ([1962] 1990), Derrida (1973) e Butler (2003); de letramentos digitais, propostos por Davies; Merchant (2009), e de conceituações de sexualidade e gênero pelas teorias queer (BUTLER, 2003; LOURO, 2004). Nesse sentido, realizei uma pesquisa de cunho etnográfico virtual (HINE, 2004) e os instrumentos de geração de dados consiste em um dos artigos de opinião encontrados no blog, que exporemos neste artigo. $\mathrm{O}$ instrumental analítico se embasa em posicionamentos interacionais propostos por Goffman $([1979], 1998)$ e nas ordens de indexicalidade de Blommaert $(2008,2010)$. Foram utilizadas como categorias de análise as cinco pistas indexicais definidas por Wortham (2001), os dêiticos (ILARI e GERALDI, 2006) e as modalizações sugeridas por Bronckart (2007). Observei que os posicionamentos interacionais encontrados nos textos são de um blogueiro do interior, que se afirma gay e ciente de sua sexualidade. Em relação às ordens de indexicalidade, constatei que o blogueiro aponta para padrões estratificados de significados referentes a normas e convenções socioculturais em detrimento de outras, como o conservadorismo das cidades interioranas, a web como espaço favorável ao relacionamento gay e a ditadura do físico belo nos relacionamentos homoafetivos.

Palavras-chave: linguagem como performance; teorias queer; sexualidade e gênero; ordens de indexicalidade; posicionamentos interacionais.

\section{ABSTRACT}

In this article, I present some reflections on the interactional positionings of sexuality and gender presented in one of the opinion articles on the blog Integra, created by students of a Federal Institute in the state of Minas Gerais, as well as identify the indexicality orders of

\footnotetext{
*Instituto Federal de Educação, Ciência e Tecnologia do Sul de Minas Gerais, Muzambinho, Minas Gerais (MG), Brasil. valeria.pereira@muz.ifsuldeminas.edu.br
} 
sexuality and gender present in it. The theoretical scope uses the concepts of performative speech acts discussed by Austin ([1962] 1990), Derrida (1973) and Butler (2003), digital literacies proposed by Davies \& Merchant (2009) and sexuality concepts and gender by queer theories (BUTLER, 2003; LOURO, 2004). In this sense, I undertook virtual ethnographic research (HINE, 2004) and the data were generated from one of the opinion articles found on the blog. The analytical tools were based on interactional positionings proposed by Goffman ([1979] 1998) and the indexicality orders of Blommaert $(2008,2010)$. The five indexical clues defined by Wortham (2001), the deictics and modalizations suggested by Bronckart (2007) were used as analysis categories. I observed that interactional positionings presented in the texts are a blogger from a small town, who affirms he is gay and aware of his sexuality. Regarding indexicality orders, I showed that the blogger points to stratified patterns of meanings regarding norms and socio-cultural conventions over others, such as the country conservatism, the web as a helpful tool to gay relationship and the beautiful physical dictatorship in homoaffective relationships.

Keywords: language as performance; queer theories; sexuality and gender; indexicality orders; interactional positionings.

\section{DA IMPORTÂNCIA DE LETRAMENTOS QUE CONSIDEREM CONTEXTOS LÍQUIDOS E SUBJETIVIDADES HÍBRIDAS}

Convivendo diariamente com jovens de origens diversas, ao longo de minha carreira docente, percebi que, por mais singular que possa ser a realidade delas/es ${ }^{1}$, comumente um fator aproxima-as/os de forma bem íntima e coloca-as/ os dentro da mesma realidade, a internet. Nos tempos atuais, em que vivemos, conforme Bauman (2001), a Modernidade Líquida, não há muros ou distâncias que impeçam a comunicação e a interação entre as pessoas, entretanto, percebi alunas/os dividindo um espaço escolar que pouco ou quase nada trata dos temas que realmente afligem a juventude, e impõe, de forma velada, um silêncio que denota força e representatividade discursivas como um Não Dito que se opõe a tudo que é dito (SEDGWICK, 2007) e que sufoca as dores daquelas/es que não se encaixam nas regras formalizadas pelas categorias de poder, criando uma cortina de fumaça para demonstrar que tudo vai muito bem.

Por isso, é importante refletirmos sobre as formas como posicionamentos sociais e declarações de juízos de valor, em absoluto, diferentes, coabitam um mesmo espaço e, por isso, discuto, neste estudo, como a web 2.0, como contexto híbrido, comporta tanto facetas tradicionais quanto contraditórias a respeito de discussões políticas, raciais, misóginas, entre outras. Assim, considerando essas novas formas de comunicação, expressão de opinião e, sobretudo, construção de conhecimento,

\footnotetext{
${ }^{1}$ As variações de gênero a(s)/o(s) e demais formas que aparecem ao longo deste artigo são utilizadas para se referir às diversas possibilidades de gênero.
} 
recorri à ideia de letramentos digitais (DAVIES, MERCHANT, 2009) para pensar as metodologias de ensino no contexto líquido a que Bauman (2002) se refere.

Acreditando que a pesquisa científica deve dialogar com as práticas sociais (MOITA LOPES, 2004), escolhi os temas sexualidade e gênero, porque compreendo o trabalho docente como oportunidade para refletir sobre o sofrimento daquelas/es que são colocadas/os na área sombria e obscura da sociedade, abordando temáticas silenciadas na escola e articuladas na web. Além disso, o trabalho traz à tona os corpos de sujeitos sociais cujas histórias eram apagadas na Modernidade. Assim, considerar os textos produzidos no blog Integra pelas/os jovens em idade escolar é um meio de ouvir esses sujeitos, atribuindo poder para suas vozes e oportunidade para expressarem e construírem suas subjetividades. A prerrogativa essencial desta pesquisa é a de que o formato digital blog e os famosos posts, como modalidades discursivas congruentes com as performances identitárias dessas/es jovens, são uma das instâncias nas quais a linguagem mais se evidencia no indivíduo como ação, sendo, portanto, signo dos paradigmas de pensamento da sociedade em questão.

Explorando um dos temas de minha dissertação de mestrado, busco expor uma análise dos posicionamentos interacionais e das ordens de indexicalidade perante temas como sexualidade e gênero em um dos artigos publicados no blog Integra, concebido e coordenado por alunas/os do Instituto Federal do Sul de Minas Câmpus Muzambinho. Para tanto, buscarei expor brevemente os preceitos teóricos que orientaram este estudo e seus preceitos metodológicos, expondo como se estruturou meu suporte de geração de dados e detalhando melhor o contexto da pesquisa para poder, por fim, apresentar alguns dos resultados e conclusões dessa pesquisa.

\section{DOS ATOS DE FALA PERFORMATIVOS COMO CONSTITUIDORES DE SUBJETIVIDADES}

Ao aprofundar-se na natureza dos atos de fala, Austin vale-se inicialmente dos termos "constatativo" e "performativo" para descrevê-los. Enquanto os primeiros são aqueles sujeitos a verdade ou falsidade, pois descrevem ou relatam algo, os últimos se caracterizam por fazerem algo, realizarem uma ação sujeita ao sucesso ou ao fracasso de acordo com as circunstâncias em que é proferida. Assim, proferimentos como "aceito esta mulher como esposa" (AUSTIN, [1962] 1990, p. 24-25) significam realizar uma ação (etimologicamente remete-se ao verbo perform realizar, efetuar) e não só declarar algo. 
É nesse sentido que Austin expõe que todo dizer é de fato um fazer, uma vez que a ocasião de um proferimento tem enorme importância e que as palavras utilizadas têm de ser, até certo ponto, "explicadas" pelo "contexto" em que se inserem, ou em que foram realmente faladas numa troca linguística. Contudo, talvez ainda nos inclinemos demasiado pelas explicações em termos do "significado das palavras" (AUSTIN, [1962] 1990, p. 89). Derrida (1973), em sua releitura dos atos de fala propostos por Austin, direciona um aprofundamento das premissas sobre as condições para o sucesso e o insucesso do proferimento, a intencionalidade e, principalmente, vale-se do conceito de iterabilidade para compreender as instâncias em que a individualidade e os ideais regulatórios relacionam-se: justamente pelo fato de o sujeito não ser plenamente consciente e não ter total domínio de sua intenção é que suas escolhas estão no campo do indecidível, do não-calculável (SANTOS, 2008 p. 1560).

Contra a suposta supremacia dos atos de fala sinalizada por Austin, e em prol de uma inerência entre repetição e linguagem, Derrida instaura a questão da citacionalidade e, por meio dela, demonstra que "a condição de possibilidade dos enunciados é a repetição, que estabelece relação com um repertório já sedimentado, repetido exaustivamente até parecer oriundo de uma essência pré-discursiva" (ROCHA, 2013, p. 42). Assim, tem-se que a repetição leva à sedimentação de significados nela implicados, o que caracteriza a essência da linguagem o aspecto performático de seus Discursos. Estendida à concepção de corpo, a questão da repetição existente na iteração torna-se mais problemática, uma vez que "sua existência [do corpo] depende de repetidos atos de nomeação - atos iteráveis." (PINTO, 2007, p.131), aspecto também explorado por Butler (2003).

Consequentemente, a reflexão de Derrida chega à passibilidade dos signos, à citação e, com isso, à chance de o sentido "romper com todo o contexto dado, engendrar infinitamente novos contextos, de forma absolutamente não saturável" (DERRIDA, 1973, p. 362). Assim, põem-se em suspensão princípios sobre os limiares da intencionalidade frente às indiscutíveis marcas citacionais reproduzidas nos proferimentos. Segundo Derrida (1973), haveria um transbordamento do conceito de linguagem que não estaria mais dando conta de tudo o que foi reunido sob ele ao longo da história do pensamento Ocidental.

\section{DAS TEORIAS QUEER E INTERSECCIONALIDADES SUBJETIVAS}

Segundo Louro (2001), é apenas na segunda metade do século XX que os movimentos em prol de uma politização dos discursos sobre sexualidade tomam 
consistência e articulam-se às discussões sociais. Mais especificamente sobre o contexto de surgimento das teorias queer, Miskolci descreve:

As origens da Teoria Queer remontam ao fim da chamada Revolução Sexual, dos movimentos liberacionistas feministas e gays e do - hoje sabemos - curto período de despatologização da homossexualidade, retirada da lista de enfermidades da Sociedade Psiquiátrica Americana em 1973. (MISKOLCI, 2014)

A conceitualização do que seria uma postura Queer produzida por esses teóricos das décadas finais do século XX poderia ser resumida na assunção da "diferença que não quer ser assimilada ou tolerada, e, portanto, sua forma de ação é muito mais transgressiva e perturbadora." (LOURO, 2004, p. 3839). Ao que Louro denomina espírito queering, interessa menos saber como as identidades sexuais hegemônicas são produzidas, e mais como determinados sujeitos e corpos são nomeados como estranhos, anormais, esquisitos ou queer

Refletindo sobre a forma como a scientia sexualis, concebida a partir do positivismo do século XIX, tem adquirido feições cada vez mais intransigentes e baseadas em verdades incontestáveis como a ars erótica medieval, Foucault (1988) demonstra que o sexo se submete a um paradigma imposto por determinadas instâncias sociais em uma espécie de recrudescimento: "Muito mais do que um mecanismo negativo de exclusão ou de rejeição, trata-se da colocação em funcionamento de uma rede sutil de discursos, saberes, prazeres e poderes; (...)" (FOUCAULT, 1988, p.70).

Assim, pode-se perceber que as concepções de sexo são conduzidas por padrões que são produtos de instâncias de determinada preeminência nos locais onde circulam e que constituem, dessa forma, uma microfísica de poder. O Discurso sobre o sexo, portanto, também está submetido ao efeito do panóptico da escola: "Em torno de cada uma dessas "representações" morais, os escolares se comprimirão com seus professores e os adultos aprenderão que lição ensinar aos filhos" (FOUCAULT, 1987, p.133).

Analogicamente, o sexo expõe-se nos Discursos como cenas persuasivas de um teatro sério; suas verdades - a inexorabilidade entre homem e mulher, o rechaço como punição aos "desvios" - circulam por entre nós e paulatinamente

2 "O Panóptico de Bentham é a figura arquitetural dessa composição. O princípio é conhecido: na periferia uma construção em anel; no centro, uma torre; esta é vazada de largas janelas que se abrem sobre a face interna do anel, a construção periférica é dividida em celas, cada uma atravessando toda a espessura da construção; elas têm duas janelas, uma para o interior, correspondendo às janelas da torre; outra, que dá para o exterior, permite que a luz atravesse a cela de lado a lado. Basta então colocar um vigia na torre central, e em cada cela trancar um louco, um doente, um condenado, um operário ou um escolar" (FOUCAULT, 1987, p.223). 
são tidas, de fato, como tais. É retomando Foucault que Judith Butler define o sexo também como uma forma de imposição de poderes e negação do desejo:

Em outras palavras, o "sexo" é um constructo ideal que é forçosamente materializado através do tempo. Ele não é um simples fato ou a condição estática de um corpo, mas um processo pelo qual as normas regulatórias materializam o "sexo" e produzem essa materialização através de uma reiteração forçada destas normas. (BUTLER, 2000, p.111112)

A autora demonstra que, até então, o Discurso biologista adotado pelos constructos sobre sexualidade atrelavam gênero (material, definido) a "sexo". Da mesma maneira, aponta a performatividade como uma forma de desconstruir aquilo que nos Discursos soa como certo/errado. Lembrando que Austin pondera que se "alguém emite um proferimento performativo, e se o proferimento é classificado como um desacerto pelo fato de o procedimento invocado não ter sido aceito, trata-se presumivelmente não do falante, mas de uma pessoa que não o aceita" (AUSTIN, [1962] 1990, p. 39), Butler (2003) propõe uma leitura do gênero pelo deslocamento, no qual a performatividade permite um discurso que vai, além do Eu, para o Outro.

$\mathrm{Na}$ perspectiva queer, aquilo que se tem usualmente por gênero acontece no interior das leis que regem os jogos de poder na sociedade, sendo por elas conformadas. Nesse sentido, são as identidades de gênero que legitimam os juízos que as fundamentam, na medida em que "são construídas e constituídas pela linguagem. O que significa que não há identidades de gênero que precedam a linguagem" (SALIH, 2013, p. 91). Isso posto, fica claro que o gênero não é uma categoria fixa e está sujeito a mudanças no decorrer do tempo, apresentandose como uma construção histórica, social, discursiva e performativa. Assim, o gênero é radicalmente independente do sexo (...)" (SALIH, 2013, p. 71).

Volto, então, à problemática derridiana da repetição de sentidos que se sedimentam na linguagem. Como Butler afirma, a sedimentação de um constructo linguístico baseado na correspondência binária sexo/gênero estabelece, involuntariamente, uma verdade preestabelecida sobre o tema:

\footnotetext{
Quando à distinção sexo/gênero junta-se uma noção radical do construtivismo linguístico, o problema é ainda pior, porque "sexo", que é definido como acima de gênero, é por si só uma indicação, construção, dada dentro da língua, como o que está diante de linguagem, antes da construção. Mas este sexo determinado como anterior à construção vai se tornar - em virtude de ser determinado - o efeito dessa aplicação para a construção. Se o gênero é a construção social do sexo e você só pode ter acesso a este "sexo" por sua construção, em seguida, aparentemente, acontece não só é que o sexo é absorvido pelo gênero, mas
} 
"sexo" chega a ser algo semelhante a uma ficção, talvez uma fantasia, retroativamente instalado em um local pré-linguístico. (BUTLER, 2002, p.23)

A questão que Butler desenvolve acima é um aprofundamento de uma reflexão ontológica que remete à natureza humana e a sua concretização no mundo através da linguagem. Para muito além das questões de gênero e sexualidade, é importante conceber como a linguagem configura, ao longo de toda a história, um conjunto complexo (e muitas vezes ininteligível) de imposição de poderes, subordinações, explorações e marginalizações, no qual privilegiam-se interesses e benefícios particulares em detrimento das subjetividades em questão.

Tal reflexão deflagra o princípio de transgressão das teorias queer sob uma perspectiva mais ampla, que envolve também a questão da interseccionalidade discutida por Miskolci (2009, p. 174-175). Logo, pode-se supor que muitos desses membros de comunidades LGBTT veem-se "deslocados do padrão identitário aceito, inclusive no mundo heterossexual brasileiro liberal" (LIMA; CERQUEIRA, 2007 , p.7), o que designa um outro silenciamento, talvez ainda mais doloroso do que o imposto pela heteronormatividade vigente que é branca, consumidora e "sarada".

As subjetivações ursinas são particularmente relevantes para o contexto de minha pesquisa, pois se relacionam intimamente com o jovem ${ }^{4}$ que assumiu as publicações do blog. $\mathrm{O}$ autor dos artigos do blog, ainda que pertença à normatividade da branquitude e não se manifeste claramente quanto ao seu poder aquisitivo, deixa bastante marcada sua oposição ao padrão físico estabelecido entre o público LGBTT. Acrescido à postura verificada nos artigos de opinião analisados, tem-se o fato de o seu biótipo não se enquadrar nos parâmetros em questão, caracterizado por alguns traços de uma manifestação subjetiva peculiar observada entre o público LGBTT, a "subjetivação ursina":

Estamos falando, portanto, de sujeitos que "se converteram" socialmente em um tipo especial de gay denominado urso. E os indícios corpóreos são importantes nestas produções. Enquanto a apresentação de um corpo com formas "maiores" do que as "normais" parece

\footnotetext{
${ }^{3}$ Cuando la distinción sexo/género se une a una noción de constructivismo lingüístico radical, el problema empeora aún más, porque el "sexo", al que se define como anterior al género, será en si mismo una postulación, una construcción, ofrecida dentro del lenguaje, como aquello que es anterior al lenguaje, anterior a la construcción. Pero este sexo postulado como anterior a la construcción se convertirá - en virtud de haber sido postulado- en el efecto de esa misma postulación, la construcción de la construcción. Si el género es la construcción social del sexo y sólo es posible tener acceso a este "sexo" mediante su construcción, luego, aparentemente o que ocurre es, no sólo que el sexo es absorbido por El género, sino que el "sexo" llega a ser algo semejante a una ficción, tal vez una fantasía, retroactivamente instalada en un sitio prelingüístico.

${ }^{4}$ Valho-me, aqui, da designação masculina para referir-me ao jovem, pois esta foi a utilizada por ele nos artigos de opinião analisados.
} 
melhor situar ursos entre "outros" gays, a maioria dos participantes, ao identificar o que é necessário para que alguém seja identificado como urso, leva em conta também a graduação e/ou soma de outros dois aspectos principais: o uso de barba e a exibição de pelos por todo o corpo. (CERQUEIRA; SOUZA, 2015, p. 274)

Do cotejo entre os estudos de Lima e Cerqueira (2007) e Cerqueira e Souza (2015), pude identificar uma estratificação de valores físicos nas iterações homoafetivas que revela duas relações: a do homem branco e sarado, mais valorizado que o homem branco e gordo, e a do homem branco e sarado, mais valorizado que o homem negro e sarado. Tomando a abordagem de cunho linguístico que Butler emprega em sua análise sobre os constructos sociais de gênero e sexualidade e associando-a à concepção sobre os processos de classificação e subjugação de minorias proposta pelas Teorias Queer é possível entender, enfim, até que ponto os artigos produzidos no blog Integra são atos de fala performativos do sujeito que os produziu, mas também um produto do contexto social em que os Discursos se constroem.

\section{DA ESCOLHA DOS MÉTODOS DE GERAÇÃO/ANÁLISE DE DADOS E SUA RELAÇÃO COM O CONTEXTO DE PESQUISA}

Sugerida pelas/os jovens com quem iniciei as discussões sobre a temática alusiva a gênero e sexualidade, a internet representa um meio propício para o desenvolvimento da questão, uma vez que, "nesse mundo, o que conta é a possibilidade de compartilhar a informação de dividi-la com outros e, assim fazendo, ampliar as redes de relações sociais" (MOITA LOPES, 2010, p.399). Logo, conforme lembram-nos Melo e Moita Lopes (2013, p.249), essa pluralidade de caminhos oferecida pela plataforma digital possibilita e favorece, também, uma percepção não apenas da realidade social que cerca o usuário, mas também uma leitura desse contexto sob uma perspectiva global de sua atualidade.

Dessa forma, a recorrência à etnografia adotada pela pesquisa compreende o que Pontes (2009, p.33) caracterizou por "construção das identidades sociais" como "um fenômeno ideológico e processual que se dá socialmente pela linguagem no jogo da interação social" e, por isso, busca inseri-la em tal dinâmica para compreender todos os fatores conjunturais que compõem os processos de indexação estudados. Tendo em perspectiva esse princípio, seria possível dizer que a proposta etnográfica de pesquisa condiz com essa postura de engajamento da pesquisadora, uma vez que, como lembram Mattos e Castro (2011, p. 37) "a própria escolha do objeto 
de estudo pressupõe estudos anteriores que levem a/o pesquisador/a a entender o campo a partir de um olhar que foi construído ao longo de sua experiência de vida". Sobre esse aspecto, Hine (2014) observa que, em um cotidiano inundado pelas TICs, é importante considerar o fato de que a interação, por meio dos recursos tecnológicos entre seres humanos, pode mudar as práticas sociais. Por isso, minha pesquisa caracteriza-se como etnográfica virtual, visto que satisfaz alguns princípios elencados por Hine a respeito dessa categoria de estudo, como:

A presença contínua do etnógrafo em sua área de estudo, combinada com um profundo compromisso com a vida diária dos habitantes desse país (...); O crescimento das interações mediadas nos convida a reconsiderar a ideia de uma etnografia ligada a um determinado local, ou mesmo para múltiplos espaços ao mesmo tempo. (...) A etnografia virtual é um interstício, no sentido de que vive entre várias atividades, tanto do pesquisador como dos participantes do estudo (...); Etnografia virtual é irremediavelmente tendenciosa. (HINE, 2014, p. 80-81)

Logo, posso afirmar que a pesquisa seguiu uma orientação etnográfica não apenas porque presenciei as reuniões para a conceitualização e concepção do blog pelas/os jovens, mas também participou do blog, acompanhando as postagens, visitando as fontes citadas ao longo delas e lendo os comentários postados.

A antiga Escola Agrotécnica (com mais de sessenta anos), fundada para a formação técnica de um curso, a princípio, para homens, contou, por muito tempo, com uma clientela cem por cento do sexo masculino e um regime disciplinar bastante rígido. Em seu cerne, atuam servidoras/es técnicas/os administrativas/os e professoras/es cuja marca predominante é heterossexual, branca e de classe média. Durante anos, a instituição representou um espaço no qual a diversidade de gênero era totalmente descontextualizada e, até mesmo, marginalizada. Atualmente, após se transformar em Instituto Federal, ganhou outra dimensão, oferecendo cursos desde o nível médio até cursos de pós-graduação. Dessa forma, seu público apresenta hoje uma extensa faixa etária e conta com uma classe estudantil mais politizada e engajada com militâncias diversas, inclusive a LGBTT.

A partir de janeiro de 2015, comecei alguns contatos com jovens que se identificavam com a causa e queriam falar sobre a referida temática, passando a realizar encontros semanais, que aconteciam dentro do espaço escolar. $\mathrm{O}$ grupo

\footnotetext{
5 "La presencia sostenida del etnógrafo en su campo de estudio, combinada com un compromiso profundo con la vida cotidiana de los habitantes de ese campo (...); El crecimiento de las interacciones mediadas nos invita a reconsiderar La idea de una etnografía ligada a algún lugar en concreto o, inclusive, a múltiples espacios a la vez. (...) $)_{i}$ La etnografía virtual es un intersticio en el sentido de que convive entre varias actividades, tanto del investigador como de los participantes del estudio.(...); La etnografía virtual es irremediablemente parcial."
} 
apresentava um perfil bastante eclético, contando com jovens entre 15 a 25 anos, estudantes desde o ensino médio integrado ao curso técnico até alunas/os de graduação. Fiz uma breve apresentação das teorias queer e a minha proposta de desenvolver uma dissertação de mestrado dentro dessa área. Ao longo dos nossos encontros, minha participação limitou-se mais a observar, ouvir e responder aos questionamentos feitos. Surgiu, então, da parte das/os alunas/os, a ideia de criar um blog que funcionasse como espaço de expressão e discussão de temas como sexualidade e gênero e pudesse servir de apoio a jovens que se identificam com a causa LGBTT e demais alunas/os do Instituto.

A ideia foi sendo desenvolvida ao longo de mais outras reuniões que ocorreram entre os meses de fevereiro e março. Nesse momento, passei a observar que as reuniões já não contavam com a presença de todas/os que iniciaram no grupo e chegamos a remarcar reuniões por ausência quase total dos membros, tornando nítido que um único aluno, chamado Erlon ${ }^{6}$, se fazia presente em todas as reuniões e se mostrava muito interessado em levar a ideia adiante. Ao término do primeiro semestre de 2015, havia quatorze postagens no blog, sendo treze de autoria de Erlon, o que mudou a orientação da pesquisa de um grupo para um indivíduo pertencente a ele. Assim, para desenvolver as análises pretendidas, orientei-me pelos posicionamentos interacionais a partir da proposição de Goffman ([1979], 1998) e pelas ordens de indexicalidade embasadas em Blommaert $(2008,2010)$.

Os posicionamentos interacionais referem-se às marcas identitárias que localizam o sujeito na vida social e o posicionam no discurso de modo singular assim como seus interlocutores. Isso significa que, em minha pesquisa, preocupeime com a projeção que o indivíduo faz de si mesmo em determinado enquadre, ou seja, "a postura, a posição, a projeção do "eu" de um participante na sua relação com o outro, consigo próprio e com o discurso em construção" (GOFFMAN apud MELO; MOITA LOPES, 2013, p. 252).

Para entendermos as ordens de indexicalidade neste estudo, recorri à noção de indexicalidade suscitada por Rocha que, embasada em Agha (2007) e Blommaert (2005), pontua:

A noção de indexicalidade é importante para compreender como comportamentos linguísticos replicáveis podem ser alterados. Ao nos engajarmos em processos reflexivos, lançamos mão de recursos semióticos que não se relacionam apenas aos usos normativos (nível denotativo). (ROCHA, 2013, p. 126)

\footnotetext{
${ }^{6} \mathrm{O}$ aluno (blogueiro) autorizou a divulgação do seu nome. Por ele referir-se a si próprio com a designação de gênero masculina nos posts, fiz o mesmo ao referir-me a ele ao longo do texto.
} 
Nessa perspectiva, segundo Rocha (2013), é preciso também entender que as ordens indexicais são resultados de uma dinâmica de interação que envolve o uso de determinado proferimento em determinado contexto de fala. Portanto, na medida em que os conjuntos de valores associados a determinados índices indexicais alteram-se, de acordo com seus contextos de uso, as análises dos mesmos também devem orientar-se por essas variáveis. Em meu estudo, adoto eixos analíticos que movimentam significados de atos de fala entre o local e o translocal, ou seja, "se o espaço se produz nas interações, toda e qualquer prática de linguagem será local, independentemente de uma compreensão mais tradicional que distribui os eventos em escalas micro e macro" (ROCHA, 2003, p.46). Por isso, é possível dizer que todo Discurso foi um dia um discurso, porém a recíproca não é válida.

Para a análise dos posicionamentos interacionais e das ordens de indexicalidade utilizo os índices linguísticos propostos por Silverstein (2003) e as cinco pistas indexicais definidas por Wortham (2001): referência e predicação, descritores metapragmáticos; citação; avaliadores indexicais; e modalizadores epistêmicos. Utilizo também os dêiticos que, segundo Ilari e Geraldi (2006, p. 66), são "palavras que mostram" e podem viabilizar a comunicação; são caracterizados, conforme Levinson (2007), por pronomes pessoais de primeira e segunda pessoas, os demonstrativos, tempos verbais, advérbios de tempo e lugar e uma série de traços linguísticos relacionados à enunciação (ILARI; GERALDI, 2006, apud MELO; MOITA LOPES, 2014, p.662).

Além dessas categorias, as modalizações também foram utilizadas e, considerando Bronckart (2007), temos as lógicas que avaliam elementos do conteúdo temático do ponto de vista de suas condições de verdade; as deônticas, que se apoiam nos valores, opiniões e regras do mundo social; as apreciativas, que avaliam os elementos procedentes do mundo subjetivo como benéficos, infelizes, estranhos e, por fim, as pragmáticas, que atribuem ao agente do conteúdo temático intenções, razões ou capacidades de ação.

\section{EXEMPLO DE ANÁLISE DE ARTIGO DO BLOG}

A título de exemplo, exponho a análise do artigo "Sentimento de estar sempre procurando...", publicado no dia 12 de junho de 2015, às 16:22 (canalintegra. blogspot.com.br). Para tornar a exposição mais didática, divido o texto do artigo em excertos que serão analisados, sucessivamente, sob o contexto geral do artigo. 


\section{Excerto 1}

1. "Sabe gente não sei se exatamente o que é, se é do meu signo ou não mais

2. sempre estou com um gostinho de quero mais na boca, sabe aquele lance de

3. pensar que nada ta suficiente ou que você sempre merece mais do que já tem,

4. sabe eu tenho toda hora."

Em linhas gerais, este artigo fala sobre a inconstância do blogueiro em suas incursões amorosas e a dificuldade que ele possui em estabelecer relacionamentos duradouros. É válido ressaltar como o tom de intimidade e informalidade do blogueiro para com os leitores já é claramente maior (o artigo de pronto inicia-se com a expressão fática e tipicamente coloquial "Sabe gente não sei se exatamente o que é $\left.(. . .)^{\prime \prime}\right)$, e seu tom confessional é perceptivelmente mais marcante do que nos artigos anteriores.

No texto, Erlon assume um posicionamento interacional de sofrimento frente a uma crise existencial, por não encontrar respostas para seus infortúnios e reflexões sentimentais. Essa marca deflagra-se na modalização apreciativa representada na expressão condicional "não sei se exatamente o que é, se é do meu signo ou não" (linha 01) e leva à ordem de indexicalidade de atribuir a fatores externos ou a terceiros a conquista da sua felicidade, como se ela estivesse sempre fora do alcance de si próprio. Perante esse sentimento de irresolução, Erlon procura justificar seu estado de alma de formas subjetivas: nas referências "signo" (linha 01) e "gostinho" e na predicação "de quero mais" (ambas na linha 02); na modalização deôntica "sabe aquele lance de pensar que nada ta suficiente ou que você sempre merece mais do que já tem" (linhas 02 e 03).

\section{Excerto 2}

5. "Sabe mais a falta maior que sinto e solidão de nunca ter amado alguém de

6. verdade, parece cliché mais não é essa a intenção, aparentemente tenho

7. esperado muito por alguém que me completasse e nessas tantas ilusões vão

8. surgindo meus casos de uma noite só, que são um caso para outro posto logo."

No excerto 2, o blogueiro demonstra um posicionamento interacional que, em certa medida, representa também um retorno aos posicionamentos assumidos no artigo anterior ("Tempestades de ilusão"), o de valorização da parceria duradoura em detrimento da efemeridade do sexo, bem marcado nas referências 
"falta", "alguém" (ambas na linha 05), "ilusões" (linha 07) "casos" (linha 08) e das predicações "'maior" (linha 05), "de verdade" (linhas 05 e 06), "tantas" (linha 07), "de uma noite só" (linha 08). Esse desejo faz-se muito forte na vida do blogueiro e suscita a ordem de indexicalidade da indissolução do casamento cultivada por uma sociedade conservadora. Tal sentimento de dor e sofrimento fica totalmente explícito nas referências "falta" e "solidão" (linha 05), na modalização lógica "aparentemente tenho esperado muito por alguém que me completasse" (linhas 06 e 07), culminando com a revelação retumbante "solidão" (referência) "de nunca ter amado alguém de verdade" (predicação) linhas 05 e 06).

Esse posicionamento do jovem apresenta-se em desacordo com a ordem de indexicalidade de um dos padrões próprios dos relacionamentos gays, que reverenciam a beleza física, a superficialidade e efemeridade dos mesmos.

\section{Excerto 3}

9. "Comigo e algo que não sei explicar ao certo sabe, toda vez que estou voltando

10. para minha casa parece que a cada passo procuro por algo não sei se

11. necessariamente alguém sabe . Tenho uma impressão de que apesar de mais

12. divertido que tudo aparente não estou completo, não sei explicar ao certo, mas

13. tenho a ideia de que seja alguém, mais nunca me aprofundei em outras

14. possibilidades, quando estou de bem comigo tenho a ideia que sou alto suficiente

15. de que me basto sozinho e tal.

16. Isso não é a pura verdade, nunca amei ninguém verdadeiramente sabe aquele

17. lance que você pensa e sente falta da pessoa, o papo flui, você gosta

18. verdadeiramente da pessoa e de como ela é."

O excerto 3 é marcado, basicamente, por modalizações que remetem a dúvida, incerteza, desconhecimento: "não sei explicar ao certo", (linha 09); "parece que ... procuro por algo ... não sei" (linha 10) "Tenho uma impressão de que" (linha 11); "não sei explicar ao certo" (linha 12) e "tenho a ideia de que seja alguém" (linha 13). Erlon também repete alguns posicionamentos interacionais já apresentados anteriormente. Do excerto 1, o posicionamento interacional de sofrimento perante suas inquietações sentimentais na referência "algo" e na predicação "que não sei explicar ao certo" (ambas na linha 09), que suscita a ordem de indexicalidade de atribuir a conquista da sua felicidade a outras pessoas que não ele próprio. Do 
excerto 2, o posicionamento de desconsolo por nunca ter tido um relacionamento verdadeiro e estável, marcado por dêiticos expressivos como os advérbios "nunca" e "verdadeiramente", pelo verbo "amei" e pelo pronome indefinido "ninguém", do trecho "nunca amei ninguém verdadeiramente" (linha 16). A expectativa por encontrar sua cara metade, seu parceiro ideal é enfatizada pela repetição da referência "pessoa" nos trechos "sente falta da pessoa" (linha 17) e "gosta verdadeiramente da pessoa" (linhas 17 e 18) e remetem à ordem de indexicalidade.da felicidade vinculada ao relacionamento estável tradicional.

\section{Excerto 4}

19. "Eu costumo dizer para mim mesmo e para os amigos mais próximos que sofro do

20. "Mal dos SETE", e você deve estar se perguntando o que o isso?, do que esse

21. cara esta falando?, calma eu explico. Eu fundamentei uma teoria pessoal chamada

22. de "Mal do SETE", funciona assim conheço uma pessoa no primeiro, segundo e

23. terceiro dia quero saber tudo sobre ela acabamos passando muito tempo juntos

24. seja por celular, e-mail, face ou pessoalmente então viro para uma das minhas

25. amigas ou amigos e digo a tão conhecida frase minha "ele tem muita coisa em

26. comum, estão encantado, estou amando" de certa forma estou acostumado a

27. fazer assim sempre, então vem o quarto e quinto dia o contato fica mais escasso,

28. então no sexto dia acabo descobrindo numa nova investida alguns defeitos e então

29. me desencanto da pessoa, em algumas vezes acabo persistindo no erro e tal mais

30. e basicamente assim que acontece."

Nesse excerto, a proximidade e a interação do blogueiro com sua audiência ficam explícitas nas marcas fáticas e coloquiais grafadas por ele nas passagens: "Eu costumo dizer para mim mesmo" (linha 19); "e você deve estar se perguntando o que o isso?" (linha 20); "do que esse cara esta falando?" (linhas 20 e 21); "calma eu explico" (linha 21); "funciona assim" (linha 22); "então viro para uma das minhas 
amigas ou amigos e digo" (linhas 24 e 25) e "algumas vezes acabo persistindo no erro e tal" (linha 29). Erlon apresenta o posicionamento interacional referente à idealização do parceiro em potencial na modalização pragmática "e digo a tão conhecida frase minha 'ele tem muita coisa em comum, estão encantado, estou amando'" (linha 25), evidenciando novamente a ordem de indexicalidade de atrelar sua felicidade a outra pessoa, o parceiro idealizado.

\section{Excerto 5}

31. A questão é que sempre estou com a porta de um ou outro aplicativo na minha

32. vida então as pessoas acabam brotando delas e tal.

33. Gente ai um de vocês me diz se sei como funciona por que não trato desse meu

34. problema, li em algum lugar acho que no meu mapa astral que tenho uma grande

35. tendência me envolver em "paixonitis" um dos meus passos pra entender melhor

36. isso e me ajudar e admitir e agora compartilhar e ir trabalhando em cima disso

37. tudo, muitas vezes tem muito haver com auto estima e tal, mais isso e assunto pra

38. outro post.

Aqui, no excerto 5, o blogueiro remete novamente ao uso de TICs, como fez anteriormente no primeiro artigo, pela referência "aplicativo" (linha 31) como um importante meio de interação para seus relacionamentos amorosos, fortemente acentuado por dêiticos como o advérbio "sempre", o pronome "minha" (ambos na linha 31) e o substantivo "vida" (linha 32). Erlon também vai retomar, aqui, o recurso já utilizado em outros artigos e também neste próprio, que é o uso do diálogo com seus leitores, estreitando seus laços de intimidade com sua audiência, na expressão coloquial: "Gente ai um de vocês me diz" (linha 33).

A crença no exotérico é marca de um posicionamento interacional que o blogueiro demonstra, quando, pela segunda vez nesse artigo, se reporta à astrologia como um expediente para explicar seu comportamento na vida amorosa. Isso ocorre, na linha 34, com a referência "mapa" e a predicação "astral" e no excerto 1, linha 01, com a referência "signo". Em contrapartida, isso nos leva novamente 
à ordem de indexicalidade de atribuir sua felicidade a pessoas e fatores externos, neste caso, tudo se explica através do seu mapa astral.

Um posicionamento interacional que remete à insegurança e ao sentimento de não pertencimento é sinalizado pelo blogueiro em quase todos os seus artigos e, neste, fica evidenciado pela modalização no trecho "tenho uma grande tendência me envolver em "paixonitis"." (linhas 34 e 35 ) e "tem muito haver com auto estima e tal" (linha 37). Esse posicionamento suscita a ordem de indexicalidade de subordinação à aparência física, ao bem-estar consigo mesmo e com seu próprio corpo, que muitas vezes leva o blogueiro à insegurança, demonstrando assim sua fragilidade com sua relação corporal.

Talvez o ponto mais relevante desse artigo seja a sua relação com os anteriores e a maneira pela qual ele conclui as principais questões levantadas ao longo deles. Depois de uma série de reflexões a respeito da superficialidade dos relacionamentos e da existência de padrões de beleza física entre os gays, bem como do seu descontentamento com isto, o blogueiro assume posicionamentos que, de certa forma, poderiam ser tomados como conclusivos frente aos demais. O primeiro deles é a assunção de uma inabilidade para lidar com essa condição amorosa paradoxal (ele espera determinados posicionamentos dos parceiros que não são os usuais e, ao que parece, se frustra com essa incompatibilidade com o padrão), verificada em expressões como "Sabe gente não sei se exatamente o que é" e "Comigo e algo que não sei explicar ao certo sabe". Sob esse aspecto, seria possível relacioná-lo à ordem de indexicalidade correspondente ao desejo frustrado de completude em um relacionamento amoroso, muitas vezes resultante de uma imaturidade emocional.

O segundo e, talvez, o mais esclarecedor em relação à questão, é a identificação de uma insegurança pessoal (que, ao longo das análises, pareceu-me intimamente ligada à aparência física e à timidez) que pode levá-lo a desacordos no relacionamento a dois, claramente expresso no trecho: "muitas vezes tem muito haver com auto estima e tal". Relacionada a esse posicionamento, tem-se a ordem de indexicalidade tocante à autoestima e à segurança em relação à subjetividade, que se demonstra extremamente importante para que o indivíduo possa estabelecer uma relação saudável e autossuficiente tanto com a heteronormatividade social que o cerca, como com as normatizações transversais que se estabelecem nos grupos LGBTTs e, principalmente, consigo mesmo. 


\section{CONSIDERAÇÕES FINAIS}

Durante o desenvolvimento da pesquisa, pude observar a relevância que o blogueiro atribui ao blog como um espaço legítimo para a discussão das questões de interesse do público gay e de interação com seus semelhantes. Ele evidencia a dificuldade de entrosamento desse público no meio social tradicional e sugere alternativas do meio virtual para favorecê-lo, o que reitera a premissa adotada pela pesquisa, segundo a qual o mundo online instaura um ambiente propício à manifestação indistinta de diversos sujeitos, tornando-se, assim, um espaço híbrido que oferece a possibilidade não só do anonimato, mas também da infinitude de alternativas para que essas/es atrizes/atores reinventem e externem suas subjetividades.

Não obstante, isso aponta também para a sua performatividade, ao criar uma alternativa para conviver nesse espaço repressivo às transgressões; ele opta por uma forma possível de se relacionar com outros gays e oferece isso como sugestão para seus pares. O jovem demonstra um posicionamento interacional consciente e autoconfiante sobre sua subjetividade homoafetiva, embora, por outro lado, explicite um comportamento contraditório, evidenciando o prestígio designado à aparência física nas relações homoafetivas e assumindo, às vezes, essa postura, mesmo que ele próprio a considere ilegítima.

Nesse sentido, ele assume essa voz de representação posicionandose sempre em primeira pessoa e referindo-se a si e a suas/seus interlocutoras/es como gays pertencentes à comunidade LGBTT. Além de ir de encontro à ordem de indexicalidade da heteronormatividade vigente nos discursos de gênero, ele também se posiciona como natural de uma cidade interiorana (o que, segundo seus textos, representa um ambiente potencializador dos preconceitos) e inferiorizado pelos padrões de beleza na comunidade gay por apresentar uma aparência ursina. Isso demonstra não apenas um posicionamento interacional de ativismo (segundo o qual se deve buscar a transformação da realidade por meio da ação, da prática efetiva) e consciência não apenas dos Discursos de gênero e sexualidade, mas de todas as categorias de Discurso que impliquem a valorização e imposição de um grupo social em detrimento de outro(s).

Outro aspecto que preponderou em minha reflexão e que pude expor ao longo deste artigo foi o de identificar as ordens de indexicalidade de sexualidade e gênero mobilizadas nas produções textuais em questão. No que diz respeito a isso, pude identificar algumas ordens de indexicalidade que se relacionam aos posicionamentos descritos acima e corroboram-nos. Logo, pode-se afirmar que as 
principais ordens de indexicalidade mobilizadas nos artigos de opinião foram as seguintes: compromisso com o grupo social que busca representar (comunidade LGBTT de maneira geral e não só do IFSULDEMINAS); dificuldade dos gays de se apropriar de um espaço na sociedade e interagir com o coletivo; marcante presença do moralismo conservador das cidades interioranas; valorização da aparência física nos grupos gays acima de qualquer outro atributo de que o sujeito possa dispor. A respeito destas três últimas, é válido ressaltar, novamente, o potencial (trans) formador da web 2,0 no cotidiano escolar, uma vez que, através dela, propõem-se discussões, questionam-se argumentos e, principalmente, agregam-se ideias: a distância não nos torna menos fortes ou menos importantes.

Ainda que se situe no contexto online, é possível pensar esta pesquisa como uma contribuição às pesquisas sobre letramento escolar, uma vez que nela se encontram os discursos produzidos pelas/os alunas/os em ambientes paralelos à escola. Com isso, demonstro-me partidária de condutas que promovem integração do contexto off-line ao universo da web, fazendo com que esta seja "compreendida como espaço de discussão, de reinvenção social, de agenciamento e de transgressão" (MOITA LOPES, 2010, p 394). Assim, considerar os textos produzidos no blog Integra pelas/os jovens em idade escolar é um meio de ouvir esses sujeitos, atribuindo poder para suas vozes e oportunidade para expressarem e construírem suas subjetividades.

Por fim, entendo que minha pesquisa já apresentou alguns frutos colhidos no sentido de introduzir os temas sexualidade e gênero no dia a dia da Escola. Acredito que, futuramente, ela poderá render outros resultados positivos para a Instituição em que atuo, apresentando (talvez através de uma nova investigação analítica) desdobramentos de uma pesquisa-ação. Da mesma forma, vislumbro demonstrar a importância de abordagens pedagógicas que se preocupem em trabalhar a temática relacionada com as questões de gênero e sexualidade nos cursos de licenciatura oferecidos pelo Instituto, contribuindo assim com a formação de professores mais bem preparados para lidar com a educação em seu sentido mais amplo e humanitário, conforme ela requer.

\section{REFERÊNCIAS BIBLIOGRÁFICAS}

AGHA, A. (2007). Introduction. In: Language and social relations. Cambridge: Cambridge University Press, p. 1-77.

AUSTIN, J. L. (1962). Quando dizer éfazer. Trad: Danilo Marcondes de Souza Filho. Porto Alegre: Artes Médicas, 1990. 
BAUMAN, Z. (2001). Modernidade líquida. Tradução, Plínio Dentzien. - Rio de Janeiro: Jorge Zahar Ed.

BENVENISTE, Émíle. Problemas de linguística geral. Tradução de Maria da Glória Novak e Luiza Neri. Ed. da Universidade de São Paulo, 1976.

BLOMMAERT, J. (2006). Social linguistics scales. London: Working Papers Urban Language \& Literacies.

BLOMMAERT, J. (2010). The sociolinguistics of globalization. Cambridge: Cambridge University Press.

BLOMMAERT, J. (2014). Ideologias linguísticas e poder; in: Daniel Nascimento e Silva, Dina Maria Marins Ferreira, Claudiana Nogueira de Alencar (orgs.): Nova pragmática: modos de fazer. São Paulo: Cortez, p.67-77.

BLOMMAERT, J. (2005). Discourse: key topics in Sociolinguistics. Cambridge: Cambridge University Press.

BRONCKART, J.-P. (1999). Atividade de linguagem, textos e discursos: por um interacionismo sociodiscursivo. Trad. Anna Raquel Machado e Péricles Cunha. 2. ed. São Paulo: EDUC, 2007.

BUTLER, J. (2000). Corpos que pesam: sobre os limites discursivos do sexo; in: Guacira Lopes Louro (org.): O Corpo Educado: Pedagogias da sexualidade. 2a Edição. Belo Horizonte: Autêntica, p.110-124.

BUTLER, J. (2003). Problemas de gênero: Feminismo e subversão da identidade. Tradução de Renato Aguiar Rio de Janeiro, Ed. Civilização Brasileira, 2003.

BUTLER, J. (2002). Cuerpos que importan: sobre los límites materiales y discursivos del "sexo". Buenos Aires, Paidós.

CERQUEIRA, P. R.; SOUZA, E. M. de L. (2015). Sexualidades e os corpos: análise das subjetivações ursinas. Revista Psicologia \& Sociedade, v. 27, n. 2.

CRAGNOLINI, M. B. D. (2007). Un pensador del resto. Buenos Aires: La Cebra.

DARDEAU, D. (2011) Jacques Derrida: da linguagem à escritura, da escritura como transbordamento. Revista Ensaios Filosóficos, v.III, p. 52-64.

DAVIES, J.; MERCHANT, G. (2009) Web 2.0 for Schools: learning and social participation. New York: Peter Lang.

DERRIDA, Jacques. (1973) Gramatologia. Trad. Miriam Schnaiderman e Renato J. Ribeiro. Perspectiva.

FABRÍCIO, B. F. (2014) Transcontextos educacionais: gêneros e sexualidades em tragetórias de socialização na escola. in: Daniel Nascimento e Silva, Dina MariaMarins Ferreira, Claudiana Nogueira de Alencar (orgs.): Nova pragmática: modos de fazer. São Paulo: Cortez, p.145-189.

FOUCAULT, M. (1987). Vigiar e punir: nascimento da prisão. Tradução: Raquel Ramalhete. Petrópolis, Vozes.

FOUCAULT, M. (1988). História da sexualidade I: A vontade de saber. Tradução: Maria Thereza da Costa Albuquerque e J. A. Guilhon Albuquerque. Rio de Janeiro, Edições Graal. 
GOFFMAN, E. (1979) Footing. In: Ribeiro, Branca Telles; Garcez, Pedro N. (eds.) Sociolinguística interacional: antropologia, linguística e sociologia em análise do discurso. São Paulo: Loyola. 1998, 70-97.

GUIMARÃES, T. F. (2014). Embates entre Performances Corpóreo-Discursivas em trajetórias textuais: uma etnografia multissituada. Tese de Doutorado. Rio de Janeiro: UFRJ, Faculdade de Letras.

HINE, C. (2004). Etnografía virtual. Coleccíón Nuevas Tecnologías y Sociedad Barcelona, Editorial UOC.

ILARI, R.; GERALDI, J. W. (2006). Semântica. 11 ed. São Paulo: Ática.

LEVINSON, S. C. (1983). Pragmática. São Paulo: Martins Fontes, 2007.

LIMA, A.; CERQUEIRA, F. de A. (2007). Identidade homossexual e negra em alagoinhas. Bagoas - estudos gays: gêneros e sexualidades, v. 1, n. 1, p. 269-286.

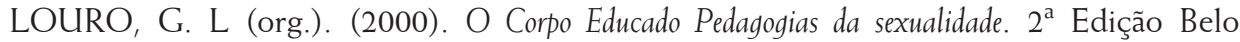
Horizonte: Autêntica.

LOURO, G. L. (2001). Teoria queer: uma política pós-identitária para a educação. Rev. Estudos Feministas, Florianópolis, v. 9, n. 2, p. 541-553.Disponível em: < http://www. scielo.br/scielo.php?script $=$ sci_arttext\&pid $=$ S0104-026X2001000200012\&lng $=e$ n\&nrm $=$ iso $>$. Acesso em: Agosto de 2015.

LOURO, G. L. (2004). Um corpo estranbo: ensaios sobre sexualidade e teoria queer. Belo Horizonte: Autêntica.

MATTOS, C. L. G. de; CASTRO, P. A. de. (orgs.). (2011) Etnografia e educação: conceitos e usos. Campina Grande: EDUEPB, 2011. Autores. 298 p. ISBN 978-85-7879-190-2. Disponível em: < http://books.scielo.org > . Acesso: abril de 2015

MELO, G.C.V.; MOITA LOPES, L.P. (2013) As performances discursivo-identitárias de mulheres negras em uma comunidade para negros na Orkut. DELTA, São Paulo, v. 29, p. 237-265.

MELO, G. C. V. de; MOITA LOPES, L. P. (2014) A performance narrativa de uma blogueira: "tornando-se preta em um segundo nascimento". Alfa, Araraquara, v. 58, n. 3, p. 541-569.

MELO, G. C. V. de; MOITA LOPES, L. P. (2014). Ordens de indexicalidade mobilizadas nas performances discursivas de um garoto de programa: ser negro e homoerótico. Ling. (dis)curso, Tubarão, v. 14, n. 3, p. 653-673, Dec. 2014. Disponível em: <http:// www.scielo.br/scielo.php?script $=$ sci_arttext\&pid $=$ S1518-76322014000300653\&ln $\mathrm{g}=\mathrm{en} \& \mathrm{nrm}=\mathrm{iso}>$. Acesso em agosto de 2015 .

MISKOLCI, R. (2009). A Teoria Queer e a Sociologia: o desafio de uma analítica da normalização. Sociologias, v. 11, n. 21, p. 150-182.

MISKOLCI, R. Comentário. (2007). Cadernos Pagu, Campinas, n. 28, p. 55-63, June 2007. Disponível em <http://www.scielo.br/scielo.php?script=sci_arttext\&pid=S0104$83332007000100004 \& \operatorname{lng}=\mathrm{en} \& \mathrm{nrm}=$ iso $>$. Acesso em: outubro de 2015. 
MISKOLCI, R. (2014). Crítica à hegemonia heterossexual. Revista Cult, $\mathrm{N}^{\circ} 193$, ano 17, agosto de 2014. Disponível em: < http://revistacult.uol.com.br/home/2014/09/ critica-a-hegemonia-heterossexual/> Acesso em: outubro de 2015.

MOITA LOPES, L. P. (1996). Contextos institucionais em lingüística aplicada: novos rumos. Revista Intercâmbio, v. 5, 1996, p.3-14.

MOITA LOPES, L. P. (2004) Contemporaneidade e construção de conhecimento na área de estudos lingüísticos. Revista Scripta, Belo Horizonte, v. 7, n. 14, p. 159171.

MOITA LOPES, L. P. (2006). Linguística Aplicada e vida contemporânea: problematização dos construtos que têm orientado a pesquisa. In: MOITA LOPES, Luiz Paulo da (Org.). Por uma Linguística Aplicada indisciplinar. São Paulo: Parábola, p. 85-108.

MOITA LOPES, L. P. (2010) Os novos letramentos digitais como lugares de construção de ativismo político sobre sexualidade e gênero. Trabalbos em Linguística Aplicada, Campinas, 49 (2), p. 393-417, jul./dez.2010. Disponível em: <http://homolog. scielo.br/scielo.php? script $=$ sci_arttext\&pid $=$ S010318132010000200006\&lng $=$ pt $\& n r m=$ iso $>$ Acesso em abril de 2105.

OTTONI, P. (2002) John Langshaw Austin e a Visão Performativa da Linguagem. D.E.L.T.A., $\mathrm{n}^{\circ} 18, \mathrm{v} .1, \mathrm{p} .117-143$.

PINTO, J. P. (2007). Conexões teóricas entre performatividade, corpo e identidades. DELTA, São Paulo, v. 23, n. 1. Disponível em < http://www.scielo.br/scielo. php? script $=$ sci_arttext\&pid $=$ S0102-44502007000100001\&lng $=$ pt\&nrm $=$ iso $>$. Acesso em: março de 2015.

PONTES, H. (2009). A Indexicalidade na Construção Discursiva de Identidades Sociais. Revista do Gelne, Piauí, v. 11, n. 1, 2009.

RAJAGOPALAN, K. (2007). Por uma Linguística Crítica. Revista Linguas e Letras, v. 8, n 14 , p. $13-20$.

RAJAGOPALAN, K. (2010). Nova pragmática: fases e feições de um fazer. São Paulo, Parábola Editorial.

RAJAGOPALAN, K. (2014). A pesquisa política e socialmente compromissada em pragmática. in: Daniel Nascimento e Silva, Dina Maria Marins Ferreira, Claudiana Nogueira de Alencar (orgs.): Nova pragmática: modos de fazer. São Paulo: Cortez, p.101-128.

ROCHA, L. L. (2013) Teoria queer e a sala de aula de inglês na escola pública: performatividade, indexicalidade e estilização. Tese de doutorado - Programa Interdisciplinar de PósGraduação em Linguística Aplicada (PIPGLA), Faculdade de Letras, Universidade Federal do Rio de Janeiro. Rio de Janeiro

ROJO, R. H. R. (2007) Letramentos digitais - a leitura como réplica ativa. Trabalhos em Lingüística Aplicada, 46, 2, p.63-78.

SALIH, S.(2013). Judith Butler e a teoria queer. Belo Horizonte: Autêntica, 2013.

SANTOS, K. C dos. (2008). Implicações da noção de sujeito na discussão da responsabilidade de fala. In: XI Simpósio Nacional e I Simpósio Internacional de Letras e Lingüística, 2008, 
Uberlândia. Múltiplas Perspectivas em Lingüística. Uberlândia: Edufu, 2008. v. 1. p. 1556-1563.

SEDGWICK, E. K. (2007). A epistemologia do armário. Cadernos Pagu, v. 28, n. 1, p. 19-54.

SILVA, L. L. da. (2015). Letramentos queer e trajetórias de socialização na "sala de aula de inglês" no ensino fundamental I. Tese de doutorado, - Universidade Federal do Rio de Janeiro.

SILVERSTEIN, M. (2003). Indexical order and the dialectics of sociolinguistic life. Language \& Communication, 23, p.193-229.

WITTGENSTEIN, L. (1953). Investigações filosóficas. Tradução: Marcos G. Montagnoli. $6^{\text {a }}$ ed. - Petrópolis. Vozes, 2009.

WORTHAM, S. (2001). Narratives in action. New York: Teacher College Press.

WORTHAM, S. (2005). Social identification beyond the speech event. Journal of Linguistic Antbropology, v. 15, n. 1, p. 31-49.

Recebido: 28/01/2016

Aceito: 10/07/2016 


\section{ERRATA}

Publicação: Trab. linguist. apl. v55n2a11, 503-524, Campinas mai./ago. 2016

Artigo: POSICIONAMENTOS INTERACIONAIS DE SEXUALIDADE E DE GÊNERO: O CASO DE UM BLOG DE ALUNAS/OS DE UM INSTITUTO FEDERAL

DOI: bttp://dx.doi.org/10.1590/010318134958176381

Pág. 503 - Inserir letra no título em inglês do artigo - deveria ser "interactional" em vez de "interational".

Onde se lê:

INTERATIONAL POSITIONINGS OF SEXUALITY AND GENDER: THE CASE OF A STUDENT BLOG AT A FEDERAL INSTITUTE

Leia-se:

INTERACTIONAL POSITIONINGS OF SEXUALITY AND GENDER: THE CASE OF A STUDENT BLOG AT A FEDERAL INSTITUTE 